\title{
SISTEMA DE FINANCIAMIENTO DE LAS PYMES -LIMA METROPOLITANA SECTOR INDUSTRIA GRÁFICA
}

\author{
SYSTEM OF FINANCING PYMES-LIMA METROPOLITAN \\ GRAPHICS INDUSTRY SECTOR
}

\author{
Ricardo Barrón Araoz* \\ Docente Principal de la Facultad de Ciencias Contables- UNMSM
}

[Recepción: Febrero de 2011/ Conformidad: Abril de 2011]

\section{RESUMEN}

El sector de industria Gráfica, a nivel de Lima Metropolitana, ha experimentado un espectacular crecimiento, tanto de tamaño micro, pequeña, mediana como de gran empresa, desarrollando diversos productos de potencial demanda.

En las últimas dos décadas el Perú experimentó cambios asombrosos, con el sistema político de la nación, pues se puso en práctica el Sistema de Regionalización, para que estas divisiones administren autónomamente sus recursos naturales; por otro lado, se crean universidades privadas, bajo el amparo del Decreto Legislativo 882, Ley de Fomento Educativo, o sea con fines de lucro. Estos cambios, crean más usuarios de diversidad de productos de la industria gráfica, que, ante el incremento de la demanda, exigen también mayores volúmenes de producción y ventas, y para ello mayores recursos de financiamiento.

El sector gráfico de empresas, igual que muchos otros sectores del Perú, se caracterizan por la presencia de empresas formales en menor proporción, mientras que el gran porcentaje están en condiciones de informalidad.

El propósito de investigación fue, determinar el sistema de financiamiento de estas

\begin{abstract}
Graphics industry sector, in Metropolitan Lima has experienced spectacular growth, both micro, small, medium and large business, developing various products of potential demand.

In the last two decades, Peru experienced amazing changes, the nation's political system, as it implemented the system of regionalization, that these divisions autonomously manage their natural resources, on the other hand, private universities are created under the under Legislative Decree 882, Law of Educational Development, or for profit. These changes, users create more diversity of products in the printing industry, which, given the increase in demand, also require higher production volumes and sales, and for this major funding sources.

The printing industry of companies, like many other parts of Peru, characterized by the presence of formal firms to a lesser extent, while the large proportion is in informal conditions.

The research purpose was to determine the system of financing of these companies to generate their output, taking into account the forms of financing are own resources or borrowed funds, as loans, credits, overdrafts, hire purchase, leasing system, the latter used
\end{abstract}

\footnotetext{
Doctor en Ciencias Contables y Empresariales - UNMSM, Docente Investigador de la Facultad de Ciencias Contables -
} UNMSM. E-mail: ricardo.20octubre@hotmail.com 
empresas para generar su producción, teniendo en cuenta que las formas de financiamiento son: con los recursos propios, o recursos ajenos, como: préstamos, créditos, sobregiros, compras a plazo, el sistema leasing, este último utilizado en Europa y Asia, con grandes ventajas para la adquisición de maquinarias sofisticadas a propósito para las industrias gráficas. El estudio solo se realizó en el área de Lima Metropolitana. Además la preocupación nuestra consistió descubrir el número aproximado de empresas formales e informales, para que estos últimos se adecuen a la ley y tengan acceso al financiamiento.

Palabras claves: Financiamiento de PYMES Y MYPES, formalidad e informalidad, mercado, industria gráfica.

\section{INTRODUCCIÓN}

Toda investigación tiene un propósito, cubrir una necesidad de la sociedad, el interés para vivir mejor en una sociedad organizada, en la que las empresas cumplan su rol preponderante en el aspecto social, y a la vez cumplan con sus obligaciones tributarias que propenderán indudablemente al desarrollo nacional. En este caso específico de las industrias gráficas, determinar el número aproximado de empresas formales e informales que operan en Lima Metropolitana.

Una vez auscultado la realidad de la informalidad en este sector, $y$ en base a las conclusiones obtenidas del trabajo de campo, es el propósito del equipo de trabajo de investigación, sugerir al Departamento del Instituto de Investigación de la Facultad de Ciencias Contables, que a través del Centro de extensión universitaria de Proyección social (CEUPS), se proceda a la orientación y asesoría de los empresarios del sector, cumpliendo estrictamente con uno de los fines principales de la universidad, de acuerdo a la Ley 23733.

\begin{abstract}
in Europe and Asia, with great advantages for the acquisition of sophisticated machinery for the printing industry purpose. The study was conducted only in the area of Lima. In addition concern was to discover our approximate number of formal and informal enterprises, so that the latter conform to the law and access to financing.
\end{abstract}

Key words: Financing of PYMES end MYPES, formality and informality, market, graphic arts industry.

La importancia del trabajo de investigación radica, no solo en determinar la situación legal de las empresas del sector gráficos, sino también sugerir a estos empresarios formados recurrir al financiamiento de su producción, mediante el sistema leasing, caracterizado por las ventajas siguientes:

1. Permite el $\mathbf{1 0 0 \%}$ de financiación del precio del equipo.

2. Permite a la empresa estar al día en la tecnología. Es decir, mitiga el riesgo de la obsolescencia, en este sector tan dinámica de los cambios.

3. Rapidez y flexibilidad.- El trámite es mas rápido en comparación con otros financiamientos, porque no exige garantías y mas cosas, puesto que la garantía principal de la empresa es la propiedad del bien materia de leasing.

4. Protege contra la inflación.- Puesto que no están afectos a posibles reajustes por inflación.

En Lima Metropolitana, según declaración de algunos empresarios hay aproximadamente 16,000 empresas gráficas; de los cuales aproximadamente existen 5,000 empresas formales, debidamente constituidas. 
Para la población de 16,000 , se calculó aleatoriamente una Muestra de 31 empresas, para aplicar el método de Encuestas.

\section{DIFICULTADES}

Al momento de aplicar el cuestionario diseñado para las encuestas, tuvimos serios inconvenientes, porque la Gran empresa no nos abrió las puertas, obligándonos en concentrar nuestro estudio en los niveles de Micro y Pequeñas empresas MYPES, constituidos por formales e informales. El análisis de trabajo de campo con sus respectivas conclusiones y recomendaciones aparecen en la sección respectiva del presente artículo.

\section{INDUSTRIA GRÁFICA}

La mayoría de los trabajos de investigación llamase de las ciencias naturales o ciencias sociales, quedan en los anaqueles o gabinetes de las instituciones universitarias por falta de medios de difusión para conocimiento del público interesado. Razón por la cual nos animamos a extractar el mencionado trabajo de investigación, con algunos aportes profesionales, debidamente actualizados a la fecha (abril 2011), para que este artículo sea publicado en la Revista Quipukamayoc del Instituto de Investigación de nuestra Facultad.

La industria Gráfica, a parte de diversidad de productos señalados en el Resumen del presente artículo, ha jugado un papel preponderante en la promoción de candidatos presidenciales y congresales, realizados el 10 de abril del presente año, con una gigante inversión que supera los 40 millones de soles, sin contar, el diseño de los spot publicitarios , las gigantografías, afiches y banderolas, con un solo objetivo, que el producto candidato, se posicione en la mente y preferencia de los "clientes" votantes.

\section{CONCEPTO DE LA IMPRENTA}

Es el arte o técnica en reproducir en papel $\mathrm{u}$ otro material, textos y figuras mediante tipos, planchas, $u$ otros procedimientos. Taller o lugar donde se imprime..

\section{HISTORIA}

Los procedimientos de la imprenta se sitúan en el año 868, del que se conserva un texto chino de Wang Chih impreso con grabados de madera y letras en alto relieve.

Después de entintarlo a mano, aplicaban el molde sobre papel de arroz. En el Siglo XI, el herrero chino Pi Sheng utilizó ya los caracteres de cada letra por separado; eran todavía los moldes de madera.

Lhang - Shi compuso la primera enciclopedia. En Europa también se aprovechó la técnica del grabado artístico para moldear cada letra por separado y juntarlas posteriormente.

El Holandés Laurens Coster, con letras móviles de madera, compuso el primer libro del que se tiene noticias.

\section{Las primeras imprentas}

Al Aleman Gutenberg se le atribuye la invención de la imprenta el año 1440.

El año 1455, se imprimió la Santa Biblia, el libro mas leído del mundo.

Gutenberg concibió y construyó por primera vez en su conjunto: confección de matrices, fundición de los caracteres, composición de los textos e impresión. Se desconoce con qué metales Gutenberg hizo sus moldes. Actualmente. Los tipos son de una aleación de plomo con estaño y antimonio, que desde la segunda mitad del siglo XIX se funden mecánicamente. 
El socio de Gutenberg, Shoffer, usó ya unas matrices de cobre. Las prensas eran manuales. Italia fue el segundo país que conoció el invento; en 1464 en Subiaco, y tres años mas tarde en Roma, implantaron dos obreros procedentes del taller de Gutenberg. También fueron tres obreros alemanes los que, en 1470, enseñaron esta técnica en Francia, de donde pasó, en 1479, a Oxford.

La primera obra que parece que salió de imprenta en España es "Obres e Trobes en labor de la Verge Maria "impresa en 1474 en Valencia, en la calle Portal de Valldigne. En 1539 el invento cruzó el Atlántico y se empezó a imprimir en México, Hasta el siglo XVIII no se avanzó demasiado en la técnica impresora. Hasta entonces, la incipiente técnica consistía en colocar los caracteres sobre la platina, encima el papel y presionar con la prensa de madera y mármol. En 1777 Didot construyó una prensa, toda de hierro y del mismo tamaño que la hoja que se iba a imprimir, que fue perfeccionándose posteriormente. En ella todavía se entintaba a mano, entre prensada y prensada.

\section{La imprenta y máquina de vapor}

En 1814 se dio un gran paso en la mecanización de la imprenta con la invención de la máquina de cilindro por konig; el molde plano pasaba sobre la superficie cilíndrica, donde estaba colocado el papel y el entintado era ya automático. El invento de la máquina de vapor estimuló y favoreció la rápida industrialización, y con ella el surgimiento, como clase dominante, de la burguesía.

Los antiguos maestros impresores fueron, cada vez más, dejando la producción directa en manos de sus obreros. Fueron así naciendo las grandes imprentas nacionales.

\section{La rotativa}

En 1854 apareció la máquina de reacción, en la que el papel, impreso por una cara, retrocedía y era impreso por la otra. Siguieron los perfeccionamientos, y en 1855 Hue registraba la primera patente de máquina rotativa.

El molde cilíndrico obtenido por estereotipia curva, presionaba contra el cilindro, imprimiendo por las dos caras, Se usaba ya el papel continuo y se hacían tiradas de 10,000 ejemplares por hora. En 1884 Mergenthaler presentó la linotipia, en la que la composición y distribución eran automáticas y en la que se fundían líneas enteras,

Nuevos perfeccionamientos condujeron a la invención de la monotipia, el año 1887, máquina que separa las funciones del teclista de las de fundición y precursora de la composición automática mediante banda perforada.

\section{La fotocomposición}

Desde comienzos del siglo XX se dieron nuevas técnicas de impresión. La aparición de la fortocomponedora hizo posible la sustitución paulatina de la composición en caliente por la composición en frío, mediante películas. Ello supuso cambiar el crisol de componedoras mecánicas por una cámara fotográfica, de manera que los textoseran directamente fdotografiados con películas, con las cuales se impresionaba las planchas destinadas a la impresión en offset o huecograbado. Eb las fotocomponedoras, a partir de un teclado similar al de las linotipias se pone en fiuncionamiento una máquina fotográfica que saca un negativo del carácter, conjunto de caracteres o gráficos dando lugar al fotolito. La impresión de ilustraciones en 
color requiere la utilización de cuatro negativos, tres para los colores primarios y un cuarto negativo en negro para resaltarlas; el resultado será una imagen con los mismos colores que el original.

Los avances mas notables actuales pasan por la utilización del láser directamente en las superficies fotosensibles de las planchas eliminando la utilización de películas intermedias. El láser accionado digitalmente mediante computadoras da lugar a unas imágenes más rápidas y perfectas que los métodos utilizados a partir de fotolitos.

\section{La edición electrónica. Autoedición}

Una de las innovaciones más drásticas introducidas en las artes gráficas es la utilización del computador a la hora de la composición y de la elaboración de las imágenes que no requieren ya de una máquina excesivamente específica, de forma que se desarrolla simultáneamente con la creación del impreso.

A partir de la década de 1970 surgieron en el mercado distintos tipos de edición electrónica, que reciben el nombre genérico de autoedición, inicialmente destinados a la producción de documentos y publicaciones con gráficos sin necesidad de un auxilio externo a las empresas. A partir de entonces, la evolución de las computadoras en cuanto a rapidez, memoria y resolución ha ido en aumento permitiendo la aplicación de cada vez mas complejos programas de audición y de diseño asistido por el computador. En este aspecto, la introducción del lenguaje y las páginas PostScript brindan unas perspectivas profesionales en el campo de la autoedición de gran futuro. El trabajo de edición electrónica proporciona una mayor rapidez y bajo costo y se entra en la composición de textos. Mediante un programa de tratamiento de textos e imágenes, preparándolos para la impresión, gracias a los propios programas de maquetación. Los gráficos pueden proceder de cualquier tipo de aplicación de imágenes, mientras que las fotografías proceden de un escáner digital, o bien directamente a partir de las actuales cámaras fotográficas digitales.
\& Fotograbado
\& Litografía
\& Grabado
\& Monotipia
\& Heliograbado
\& Offset
\& Huecograbado
\& Rotativa
\& Gutenberg
\& Linotipia
\& Tipografía

\section{INDUSTRIA GRÁFICA PERUANA}

* Se ilustra este artículo con aporte de la prestigiosa revista AGUDI, (medio de difusión de la Asociación Gráfica Unión de Imprentas).

\section{AVANZANDO FIRME HACIA LA EX- CELENCIA Y LA CALIDAD}

Dos importantes acontecimientos han situado al territorio peruano en el centro de la atención, pues, el $1^{\circ}$ de octubre lo más destacado de la industria gráfica nacional e internacional se dará cita en una noche que pretende ser inolvidable. Los 90 años de Agudi y la Premiación de los Ganadores del XVI Theobaldo De Nigris, dos celebraciones simultáneas compartirán protagonismo en la Gala Gráfica Latinoamericana.

Gala que conmemorará las 9 décadas de la asociación pionera de América Latina, Asociación Gráfica Unión de Imprentas - Agudi. Destacada institución gremial peruana que forjó sus cimientos en 1919 de la mano de hombres visionarios, dueños de las principales imprentas, personajes ilustres que lograron congregar a las grandes, medianas y 


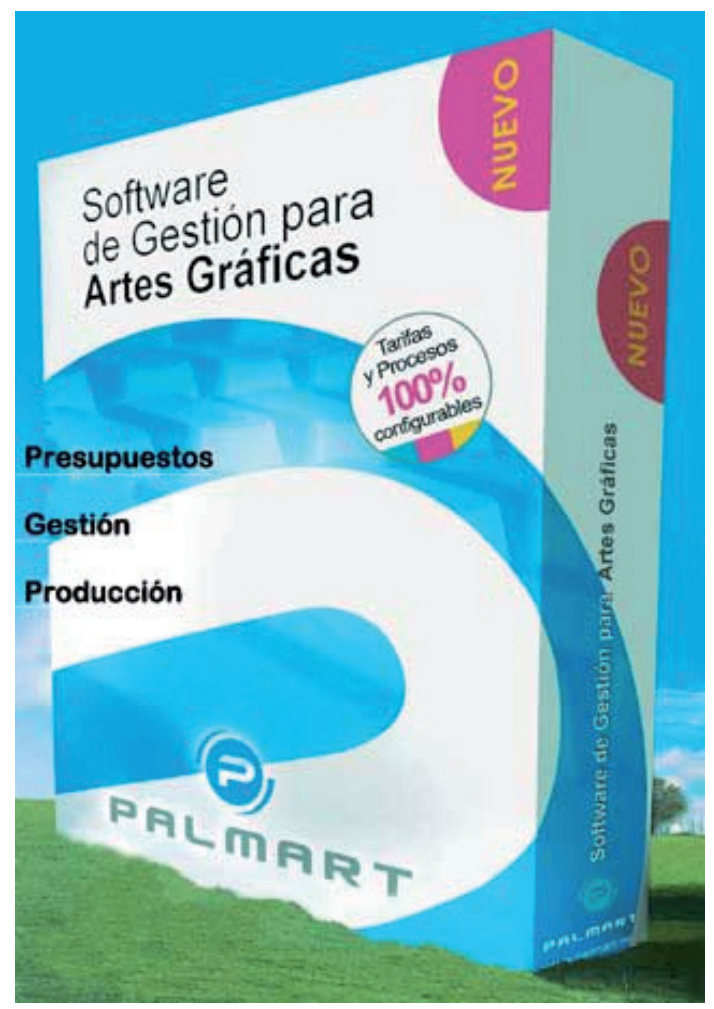

pequeñas imprentas, brindando un espacio preferencial a la industria gráfica emergente de esos años.

En el devenir de Agudi, diversos hechos han marcado y construido la historia gráfica en el Perú; sus constantes reuniones con el Sindicato Gráfico de Lima debatiendo sus pliegos de reclamo y buscando siempre la solución más armoniosa, los congresos y la serie de seminarios dirigidos a proporcionar información de primera mano para capacitar al personal de las diversas empresas y las acostumbradas reuniones en los salones del antiguo e histórico local institucional.

Pasillos llenos de recuerdos y anécdotas, personajes imborrables en nuestra memoria, ideales intactos e inquebrantables que se perpetuarán en cada hombre que asuma Agudi como parte suya.

Además, dotando de autenticidad la velada, se suma otro magno acontecimiento: la Premiación del Theobaldo De Nigris, concurso que hoy refleja el nivel de competividad y calidad en el que se encuentra la industria de nuestro país, con empresas a la vanguardia de la industria mundial, con tecnología de punta y destacado talento humano, que han hecho del sector gráfico uno de los sectores más potenciales y con gran fuerza y presencia en la economía peruana. Tanto es así que empresas peruanas se han visto galardonadas con importantes distinciones a nivel mundial, los premios Benny y FTA.

El sector gráfico nacional se encuentra en un crecimiento progresivo y vislumbra un futuro positivo, lo cual podemos confirmar en las iniciativas de formalización de los pequeños empresarios del Centro Lima -donde se acopian gran cantidad de impresores-, quienes, buscando alejarse del seudonegocio de la informalidad, se han reordenado en las antiguas instalaciones de la empresa Diamante en la avenida Argentina.

Así, a medida que el empresariado tome conciencia sobre las verdaderas repercusiones de trabajar de manera ilegal y de lo transcendental de la formalización, la industria gráfica peruana podrá ganarse un lugar prestigioso en el mercado mundial, donde priman las grandes potencias gráficas.

Por último, pero no menos importante, por cuarta vez en nuestro país se desarrollará la Asamblea Ordinaria Conlatingraf, que reunirá a los representantes de las asociaciones amigas de Latinoamérica para debatir diversos temas de relevancia mundial. Le damos la más cordial bienvenida a las delegaciones internacionales y les extendemos las manos para estrechar los lazos de confraternidad y colectividad a favor del desarrollo de la industria latinoamericana. Esta $73^{a}$ Asamblea concluirá con la celebración del aniversario de la asociación y con la premiación del Concurso.

Por todo lo anterior, la noche del jueves primero de octubre no sólo será de Agudi 
sino de todos y cada uno de las personas y empresas que acompañaron, acompañan, creyeron y aún siguen creyendo en esta su institución: Agudi $90^{\circ}$. Por su aniversario, ¡un brindis que une a todo el empresariado gráfico del Perú!

\section{LOS MEJORES TRABAJOS GRÁFICOS YA ESTÁN EN LIMA}

Cumpliendo con su compromiso con la calidad y excelencia en cada uno de sus productos impresos, países como México, Argentina, Brasil, Colombia, Venezuela, Guatemala, Chile, Ecuador, Costa Rica y por supuesto el Perú enviaron más de 1000 productos para esta nueva versión del famosísimo Theobaldo De Nigris.

Cifra que pone al Perú -primera vez sede del certamen- como una de las asociaciones con mayor convocatoria en estos 16 años que se viene realizando tan magno evento.

\section{La convocatoria}

A inicios del mes, de julio Agudi empezó una incesante y permanente campaña llamando a participar a las empresas más representativas del sector en el Perú y en las asociaciones de nuestra región.

Así, por medio de sus reconocidas herramientas de comunicación, dedicó semana tras semana a mantener informado al empresariado nacional y extranjero. Pasando desde la historia de Conlatingraf y el prestigioso Theobaldo De Nigris hasta los últimos detalles que en nuestra calidad de organizadores venimos afinando.

Los boletines electrónicos se convirtieron en el canal para llegar a miles de lectores que asiduamente revisaban nuestro medio para enterarse sobre lo más resaltante del concurso. Con un nuevo cambio de diseño,

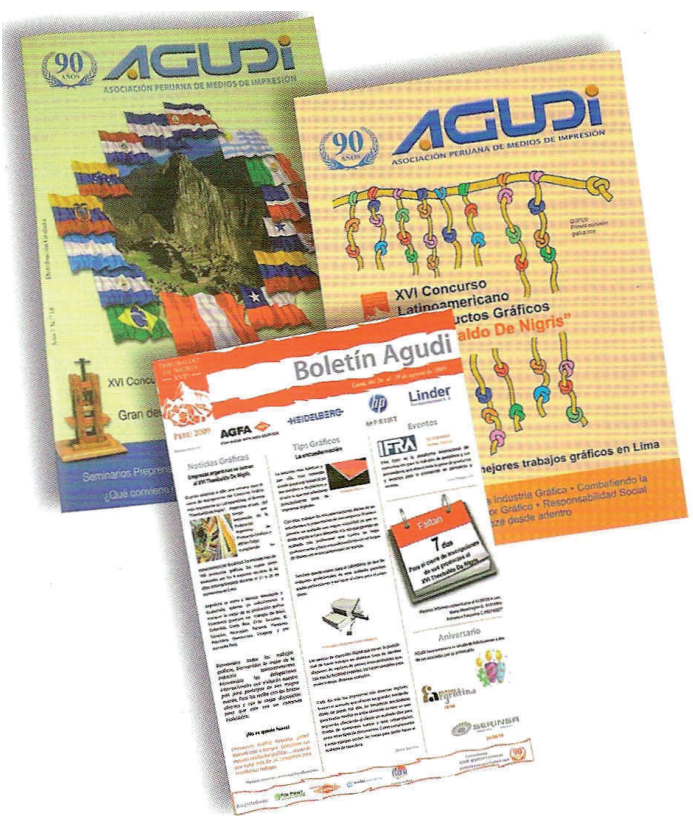

exclusivo del TDN09 hacia la cuenta regresiva para este importante día.

Y la revista Agudi no dejaba de publicar en sus páginas ediciones seguidas y extraordinarias de todo lo referente al certamen, además con el relanzamiento de la página Web se potenció el canal electrónico llegando a muchos más usuarios.

\section{Visita a las empresas peruanas}

Uno de los puntos fuertes de la campaña y el que demostró mayor eficacia fue la serie de visitas realizadas a las empresas peruanas. Una delegación de Agudi se encargó exclusivamente de visitar a las compañías con mayor incidencia en el sector, logrando que la participación peruana en esta ocasión fuera desde lejos superior a años anteriores.

Las visitas se prolongaron por dos meses, aprovechando la gentileza de las empresas en brindar a Agudi un espacio especial en su ajustada agenda de trabajo. Espacio en que la delegación se encargó de dilucidar toda clase de dudas, contribuyendo a crear una costumbre más participativa y de sana competencia en el sector. 
Trabajando simultáneamente a través de la red o en visitas personalizadas, explorando y explotando cada opción, Agudi se aplicó a la tarea para garantizar el éxito de esta versión del Theobaldo.

Hasta que por fin los teléfonos de la institución comenzaron a sonar, empresas peruanas se vinculaban al TDN09.

\section{Comienzan a llegar los productos}

Mientras la Directiva de Agudi, el Comité organizador y todo el valor humano se encargaban de elaborar y poner en marcha cada pormenor del proceso, los frutos de su labor empezaron ha cosecharse.

El primer país en hacerse presente fue México con alrededor de 314 productos, luego la tierra del tango, Argentina, se uniría; sumándose luego Venezuela, Guatemala, Brasil, Ecuador, Colombia, Chile y Costa Rica.

Los empresarios peruanos no se mantuvieron al margen, pues conforme llegaban los productos del exterior, los trabajos peruanos también llenaban su espacio en el salón del local institucional.

Poco a poco el salón acondicionado para resguardar las piezas gráficas se volvía más pequeño, ya que a medida que la fecha del cierre de inscripción se daba a conocer por la Web las piezas abarrotaban cada vez más el lugar. Nadie quería quedarse sin participar.

\section{Delegada de Conlatingraf en Lima}

Para dar conformidad al proceso de inscripción, cotejar que los productos se encuentren en las mejores condiciones -en el viaje pueden suceder inconvenientes-, que cada pieza esté en orden con su respectiva ficha y sobre todo dejar en el anonimato los trabajos, así garantizar la imparcialidad de los jurados, arribó a nuestra tierra Margarita Cáceres, de-

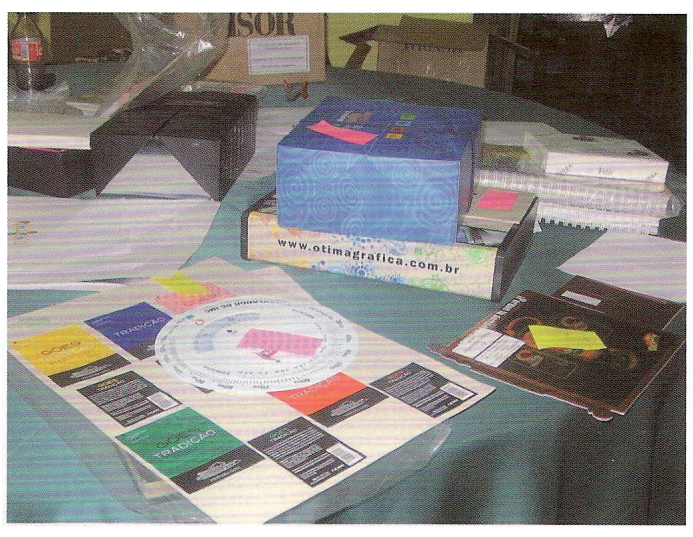

legada de Conlatingraf. A quien sus catorce concursos avalan su data experiencia.

Durante tres infatigables días, junto al equipo de Agudi, Margarita se dedicó a la ardua labor de revisar minuciosamente cerca de 1200 piezas. Con sumo cuidado y dedicación fueron clasificándose los trabajos, los cuales aguardarán hasta el 21 de setiembre hasta que los 5 jurados internacionales y 2 compatriotas nuestros se dediquen a su evaluación.

\section{EPSON PRESENTA UNA NUEVA GE- NERACIÓN EN IMPRESIÓN DE GRAN FORMATO}

\section{Con tecnología doblemente más rápida que cualquier otro equipo}

El fabricante de tecnologías para la imagen, Epson, está lanzando una nueva generación de impresoras de gran formato, ideales para la industria de artes gráficas. Los nuevos plotters Stylus Pro 7900 y 9900, de 24 y 44 pulgadas respectivamente, ofrecen impresiones de gran calidad a una velocidad dos veces mayor que el resto.

Estos modelos de plotters incorporan los nuevos cabezales MicroPiezo TFP, con un excelente rendimiento en la impresión y precisión en la colocación del punto. Juan Carlos Morante, product manager de la compañía señaló que MicroPiezo TFP podría 


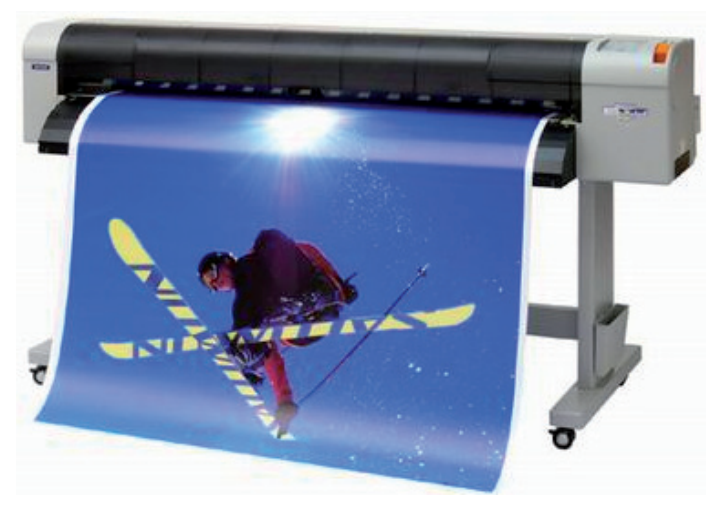

ser la tecnología de cabezal de impresión de inyección de tinta más avanzada que se haya desarrollado hasta la fecha.

Igualmente, la línea Stylus Pro 7900 y 9900 incluye la nueva tecnología de inyección de tinta Ultrachrome HDR, creada por Epson, para lograr una mayor calidad de impresión y mejor gama de colores. Con esta tecnología EPSON establece un nuevo estándar en la impresión con inyección de tinta a nivel profesional.

La nueva tecnología Ultrachrome HDR incorpora los colores naranja y verde de modo que la utilización de 10 colores representa una completa innovación en sistemas de impresión de pruebas de color y fotografía digital, convirtiéndose así en productos ideales para profesionales que buscan tonos cada vez más reales y nítidos.

El buen desempeño del equipo está garantizado debido a su robusto diseño que cuenta con nuevo e innovador sistema de rollo sin eje, un controlador con tecnología exclusiva que aprovecha al máximo el sistema de tres niveles de negro para producir impresiones profesionales en blanco y negro a partir de archivos de imágenes a color o en escala de grises.

Además, el ejecutivo agregó que los profesionales podrán hacer ajustes precisos de color y así lograr impresiones verdaderamente personalizadas en blanco y negro.
La nueva tecnología Epson abre nuevas oportunidades a 105 profesionales de la industria de impresión y diseño, ofreciendo equipos más eficaces que permiten reducir gastos innecesarios originados por ineficientes pruebas de color.

\section{EMPRESAS GRÁFICAS PERUANAS AMIGABLES CON EL MEDIO AM- BIENTE}

Agudi reconociendo la iniciativa de las empresas gráficas orientadas a implementar medidas ecoeficientes que mejoran la competitividad empresarial, incentivan el aprovechamiento eficiente de los recursos naturales y sobre todo realizan prácticas que garantizan la protección de la calidad ambiental, muestra a continuación el caso de dos empresas responsables que ya pusieron manos a la obra y comenzaron el camino hacia la Producción Limpia.

Además, hace un llamado especial a las empresas del Perú a que empiecen la toma de conciencia sobre lo importante que es preservar nuestro medio ambiente, asimismo, felicita a las empresas que ya están adoptando medidas hacia la ecoeficiencia.

\section{Solvima Graf vocera del cuidado del me- dio ambiente}

Para Soledad Laguna, Gerente General de Solvimagraf, el medio ambiente es un tema que compete tocar a todos, porque si ahora no se convierte en una prioridad protegerlo y cuidarlo dentro de muy poco tiempo se sufrirán las consecuencias. "Nosotros (Solvimagraf) nos sentimos muy identificados con el tema, además en un sentido muy particular, porque venimos trabajando a través de la impresión de revistas o folletos al Ministerio del Ambiente. Entonces ellos 


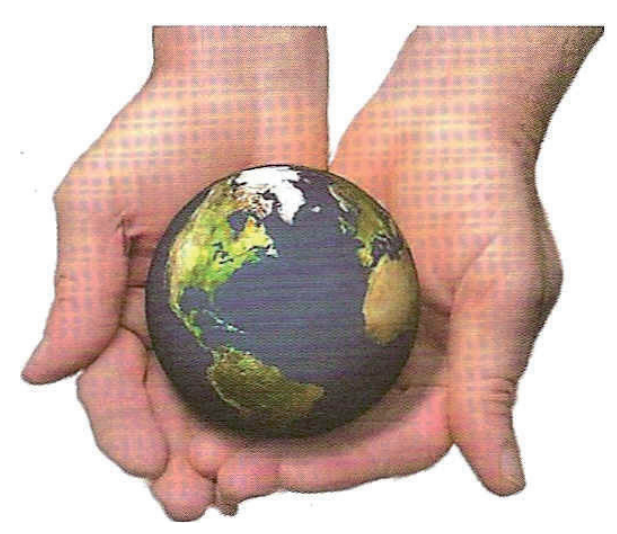

están viendo como concientizar a todo el público en general, para que haya cultura de reciclaje, de reutilizar los residuos tanto sólidos como líquidos para poder darle un mejor uso sin contaminar."

Además, comentó que actualmente están elaborando todo el material de difusión de las Municipales ecoeficientes.

A raíz de ello, el próximo año Solvima participará en el Concurso Empresas Ecoeficientes que organiza el Minam, por eso están por implementar políticas de reciclaje de papeles, botellas, pilas, envases de tintas, entre otros que son altamente contaminantes. Cristalizando este proyecto en la medida que Solvima se afiance más en este nuevo local.

"No solo colaboramos con el ambiente apoyando la producción limpia en nuestros procesos, sino informando a la gente sobre la importancia de preservar, utilizando ambos canales esperamos contribuir a la toma de conciencia, con nuestras áreas naturales", explicó.

\section{METODOLOGIA DE INVESTIGA- CION EMPLEADA}

Para el estudio planteado se procedió a los siguientes métodos:

- Método Descriptivo.- Para describir la diversidad de impresiones que produce el Sector de industria Gráfica.

- Método Analítico.- Para comparar diversos tipos de financiamiento que hemos logrado obtener mediante la encuesta, para escoger el sistema mas adecuado, de bajo costo y de fácil acceso.

- Método Deductivo.- Mediante la encuesta a los productores de impresiones para determinar las condiciones de formalidad e informalidad de sus negocios.

- Métodos gráficos para ilustrar los resultados.

\section{TABAJO DE CAMPO}

Se aplicó el método de Encuestas a los propietarios de imprentas de Lima Metropolitana, entre empresarios formales e informales.

No se puede precisar con exactitud el número de empresas gráficas que operan en Lima Metropolitana, pues cada Distrito registra independientemente todos los negocios de su jurisdicción, entre estos las empresas gráficas.

Los Municipios son muy celosos de proveer la información requerida. Por otro lado, en el supuesto de acceder a la información de los gobiernos locales sobre las industrias gráficas, solo estaríamos cubriendo una parte incompleta de nuestro trabajo de investigación, cuya propósito consiste, que mediante el estudio de mercado encontrar el número aproximado de industrias gráficas de Lima Metropolitana, y de estas el porcentaje de formales e informales que operan en dicha jurisdicción, , el tamaño de estas empresas, llámese micro, pequeña, mediana o Gran empresa y finalmente, qué tipo de financiamiento emplean para sus negocios.

De este modo se aplicó el método de ENCUESTAS a los supuestos de tamaños micro, pequeña y mediana empresa y a los de Gran Empresa. Fue necesario y preciso entrevistar al señor Eloy Noceda Martorellet, Presidente del gremio de este sector, denominado ASOCIACION PERUANA DE MEDIOS DE IMPRESIÓN. 


\section{APLICACIÓN DEL METODO DE EN- CUESTAS}

Según el Gremio Asociación Peruana de Medios de Impresión, en Lima Metropolitana hay aproximadamente 16,000 Empresas Gráficas; de las cuales aproximadamente existen 5,000 empresas formales, o sea debidamente constituidas y 11,000 en condiciones informales.

\section{Procedimiento.}

Población aproximada 16,000

Muestra aleatoria 31

Se calculó la muestra en forma aleatoria simple

Se aplicó la encuesta a los industriales de imprenta básicamente, en los lugares de mayor número de instalaciones de estos negocios de Lima: en el Centro Civico, por las avenidas Rufino Torrico, Huancavelica y en los Distritos industriales de Villa del Salvador, Ate y Sanata Anita.

\section{METODO DE ENCUESTAS Y ENTREVISTAS}

1 ¿Desde cuando se dedica Ud. a este negocio?
a) 1 año
b) 2 años
c) 5 años
d) Mas de 5 .

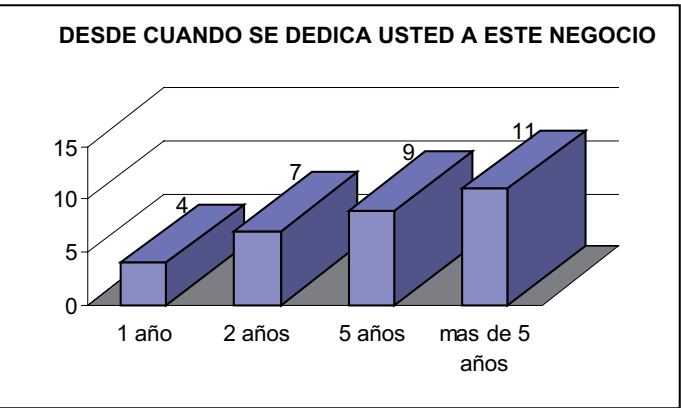

A la pregunta desde cuándo se dedica Ud. a este negocio, respondieron 11 encuestados, que representa el $38 \%$ desde hace más de 5 años y 9 que representa el $30 \%$ por 5 años. Estas respuestas indican que no se trata de empresas improvisadas, sino de empresas firmes en su s decisiones son empresas de éxito.

\section{2. ¿Qué tipo de productos generan en su empresa?}

Los productos generados son:

a) Papeles membretados 30

b) Talonarios de boletas de venta 19

c) Talonarios de facturas 25

d) Almanaques 21

e) Gigantografías $\quad 17$

f) Tarjetas personales 28

g) Tarjetas de matrimonio $\quad 17$

h) Capillos 27

i) Otros 22

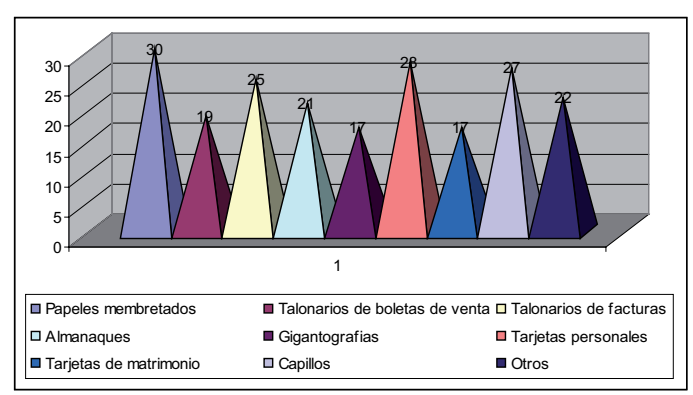

Al formular, qué tipos de productos mayormente producen en su empresa, esta pregunta el $96 \%$ o sea de 30 imprimen los papeles membretados; el $92 \%$, o sea 28 se dedican a la impresión de las gigantografías, sigue en ese orden, la elaboración de los capillos , talonarios de facturas. etc. En conclusión, casi todos elaboran los productos conocidos que satisfacen a las personas naturales como jurídicas. 


\section{3. ¿Con cuantos trabajadores cuenta su} empresa?

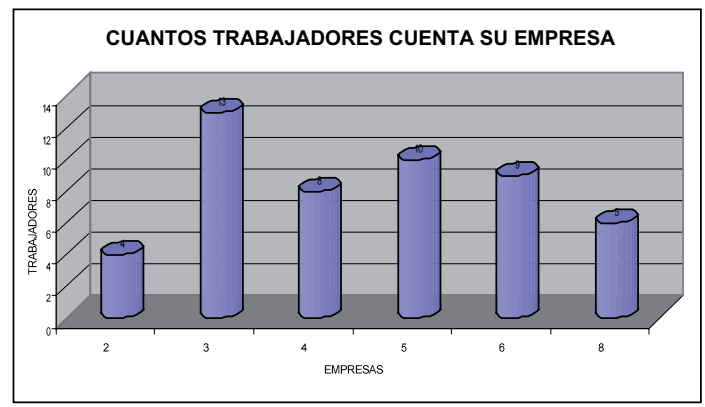

A la pregunta, ¿Con Cuántos trabajadores cuenta su empresa?, respondieron: 3 empresas tienen 13 trabajadores $\mathrm{c} / \mathrm{u}$ 5 empresas tienen 10 trabajadores $\mathrm{c} / \mathrm{u}$ 6 empresas tienen 9 trabajadores $\mathrm{c} / \mathrm{u}$

$\mathrm{Y}$ así en las demás empresas encuestadas el número de trabajadores son menores.

Lo que indica que casi la totalidad de las empresas encuestadas están comprendidas en tamaño de micro y pequeñas empresas MYPES.

\section{4. ¿Para financiar su negocio, a cual de} los siguientes sistemas recurre?
a) Prestamos bancarios
b) Crédito directo de las empresas 16
c) Sobregiro bancario
d) Con sus propios recursos
e) Sistema Leasing

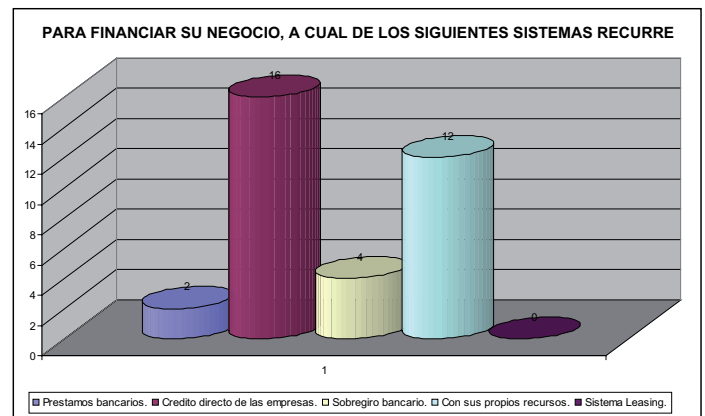

$\mathrm{Al}$ preguntarles, qué tipo de financiamiento emplean para sus negocios, el $78 \%$, o sea 24 encuestados manifestaron que recurren al crédito directo de las empresas pro- veedoras y el $22 \%$, o sea 7 , recurren a sus propios recursos. El financiamiento por bancos tiene poca preferencia.

5. Si no recurre al financiamiento de su empresa mediante sistemas señalados, es por:

a) Los intereses muy altos

b) Tramites engorrosos, complicados

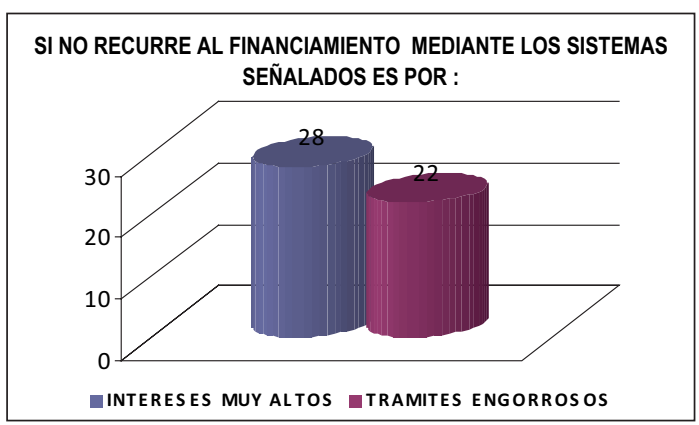

A la pregunta, Porqué no recurren a prestamos de bancos, los sobregiros bancarios e incluso al sistema leasing. El 92\%, 0 sea 28 por que los intereses son muy altos y el 70 \% ó sea 22 por los trámites son engorrosos.

6. El financiamiento por el sistema Leasing, principalmente es para comprar maquinarias y equipos modernos para la industria gráfica; entre sus ventajas, se caracteriza: no necesita una cuota inicial, no necesita garantías, ni comercial, ni personas con solvencia económica; mantiene actualizada con la última tecnología. Con las ventajas señaladas del leasing ¿Ud. optaría por este sistema financiamiento?

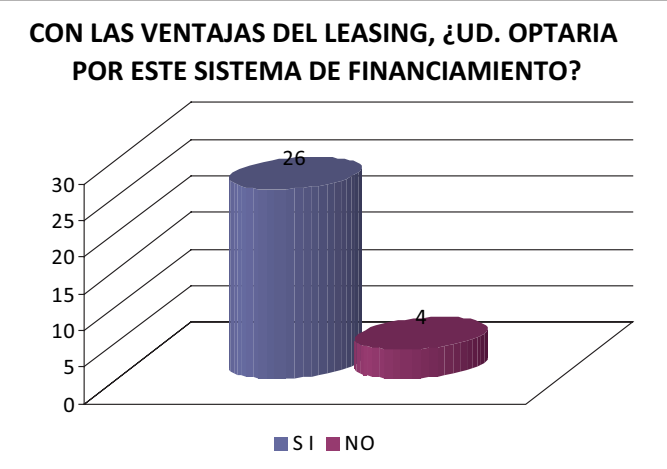


En esta pregunta se hizo una introducción por las ventajas del sistema de financiamiento por leasing y luego se preguntó si optarían por este sistema de financiamiento para impulsar su negocio; el $87 \%$, o sea 26 encuestados respondieron que sí y el 13\%, respondió que no. Con lo cual se concluye que el sistema de leasing no es conocido, y con mayor asesoramiento pueden elegir este tipo de financiamiento.

7. Su empresa esta formalizada:

g) $\mathrm{Si}$

h) No

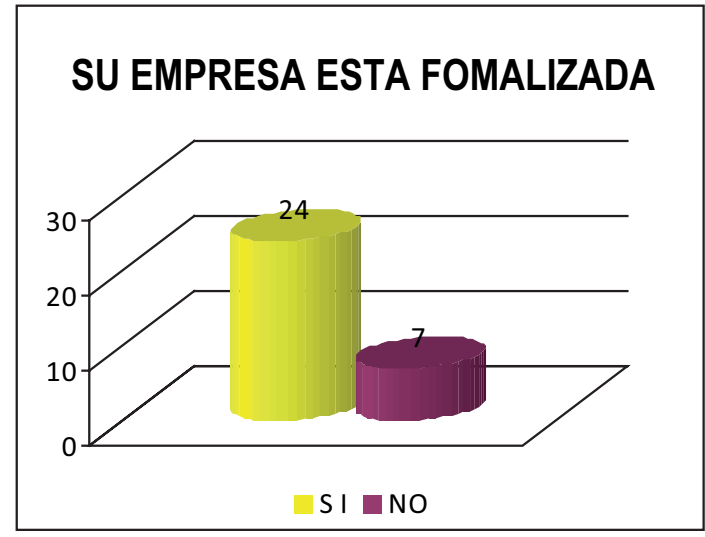

Al plantearles la pregunta, si su empresa está formalizada, respondieron el $78 \%$ que sí, o sea 24 y el $22 \%$, o sea 7 , que no está formalizada. Uno de los objetivos de esta investigación fue, encontrar el número de empresas en situación de informalidad, luego ayudarlos a que formalicen tengan acceso al financiamiento de terceros, consecuentemente potenciar su producción.

8. Si no estuviera formalizada,,$\dot{i}$ Ud. Estaría dispuesto adecuarse a la formalidad, con el asesoramiento de nuestra universidad?
a) $\mathrm{Si}$
b) No

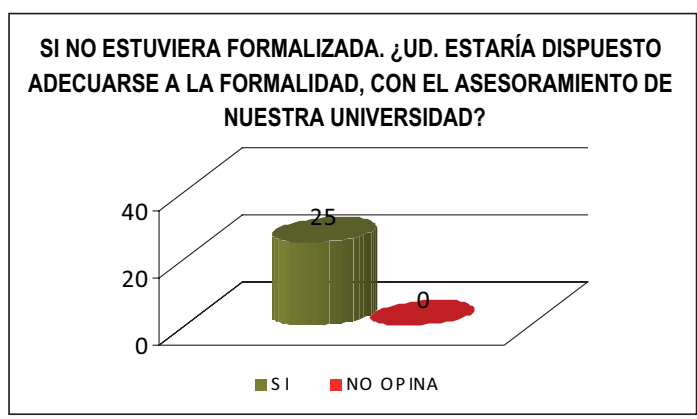

En nuestro deseo de ayudar a pasar a la formalidad del $22 \%$ de informales, se preguntó, si estarían dispuestos a pasar a la legalidad. A esta pregunta respondieron que sí estarían por pasar a la legalidad.

\section{Usted esta contento con su empresa} actual o estaría dispuesto a cambiar de negocio.
a) $\mathrm{Si}$
b) No

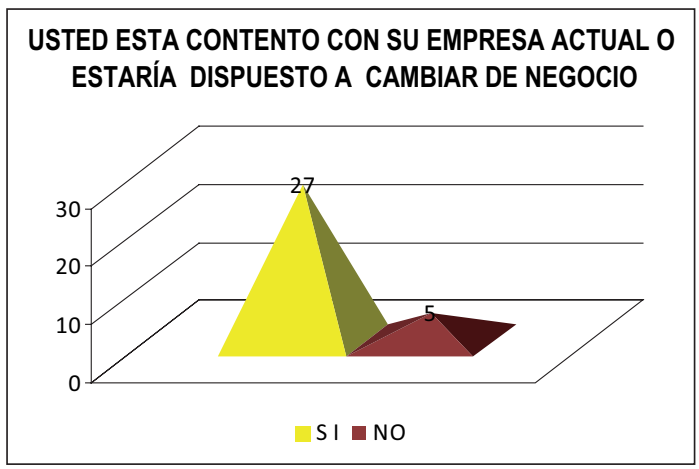

Por último se planteó la pregunta, si está contento con su empresa actual o estaría dispuesto a cambiar de negocio. A esta pregunta respondieron el $89 \%$, o sea 27 encuestados que sí, lo que indica que el negocio de gráficos es un sector con futuro, que a medida que aumenta la población, aumenta también los negocios , consecuentemente crece la necesidad de uso de esos productos gráficos. El sector gráfico es una actividad sostenible para cubrir la demanda siempre creciente. 


\section{CONCLUSIONES}

1. De acuerdo a los resultados de la Encuesta realizada a los empresarios gráficos, preguntando el número de trabajadores que laboran en sus negocios, llegamos a la conclusión que el número máximo de trabajadores llega a 13, lo que indica, que las empresas encuestadas están en el rango de micro y pequeñas empresas, o sea las MYPES.

2. Las empresas grandes como la Xerox del Perú. Quebecor Wor y EPSON, no nos accedieron para una entrevista, menos responder el cuestionario elaborado al tamaño y nivel de sus negocios. Pareciera que existe la política de cierrapuertas para los investigadores de universidades que quieren conocer.

3. En cuanto a la situación legal de las empresas encuestadas, se desprende que la mayoría declara que son formalizados y solo el $22 \%$ que no.

Y los que no están formalizados, estarían decididas a formalizarse con el asesoramiento de un organismo como la U.N.M.S.M. a través del Centro de Unidad de proyección Social. CEUPS.

4. En cuanto al financiamiento de sus empresas, el $78 \%$ optan por créditos directos de las empresas proveedoras, y el $22 \%$ lo hacen con sus recursos propios o con el capital que poseen y si generan márgenes de ganancias lo destinan a la reinversión.

5. Con la introducción que se hizo sobre las ventajas del Sistema de Financiamiento por Leasing, para bienes de equipo que requiere la industria gráfica, los empresarios manifestaron favorablemente por este sistema de financiamiento

6. Según la entrevista formulada a algunos empresarios manifiestan que en Lima Metropolitana hay aproximadamente 16, empresas gráficas de diferentes tamaños, de este total, sólo 5,000 son formales y los 11,000 están en condiciones informalidad .

7. A formular las preguntas a los empresarios, si se encuentra contento con su negocio, manifiestan que si. Lo que indica que este sector tiene futuro, pues cuanto mas aumenta la población también aumentan los negocios y consecuentemente crecen las necesidades de este rubro para satisfacerlas. Por lo tanto será indispensable los productos gráficos a pesar de que el mundo actual vive la era virtual.

\section{REFERENCIAS BIBLIOGRÁFICAS}

1. Investigación de Mercados Tomas C. Kinnear Edit.Mc Graw Hill. Mexico 2002.

2. Marketing Estratégico Ricardo barrón Araoz Edit. Herrera Asoc. Lima - 2000.

3. Marketing y Ventas José M. Ferré Trenzano Ed. Ocean/Centrum José Ramón Bibinat Barcelona- España 2005

4. Estadísticas del INEI

5. Revista de AGUDI "Asociación Peruana de Métodos de Difusión” 2009. 